\title{
The Status and Determinants of Solar Photovoltaic Technology Utilization by Rural Households in Gozamin Woreda, Amhara National Regional State, Ethiopia
}

\author{
Yared Alazar Alehegn \\ School of Environmental and Natural Resource Studies, Hawassa University, Wondo Genet, Ethiopia \\ Email address: \\ yaredalazar@gmail.com
}

To cite this article:

Yared Alazar Alehegn. The Status and Determinants of Solar Photovoltaic Technology Utilization by Rural Households in Gozamin Woreda, Amhara National Regional State, Ethiopia. International Journal of Energy and Environmental Science. Vol. 4, No. 2, 2019 , pp. $27-34$.

doi: $10.11648 /$ j.ijees.20190402.11

Received: May 27, 2019; Accepted: July 2, 2019; Published: July 12, 2019

\begin{abstract}
Solar Photovoltaic technology has been advanced in the world as a renewable energy source many years ago. The progress of the technology is due to its social, economic and environmental benefits. However, utilization of solar photovoltaic technology by rural households in Ethiopia is a recent phenomenon with low rates of use. Hence, this study was conducted to meet the aim of exploring the status and determinants of solar photovoltaic technology utilization by rural households in Gozamin woreda. Three kebeles were purposively selected to conduct the study. Simple random and stratified sampling methods were used to get representative samples. Primary data and secondary information were also collected from households and reports, magazines, journals, etc. A total of 190 representative household samples were selected. Binary logit model was used to analyze the correlation between utilization of solar photovoltaic technology and explanatory variables. Descriptive statistics was also conducted to analyze the functionality, patterns and constraints of SPV technologies. The result of descriptive statistics showed that all the diffused technologies were functional. Despite this, 23.4 percent of SPV technologies fail to function once or twice per month due to weather conditions and technical incapability. Lighting was the major pattern of use by all (60) users. Additionally, 78.3 and 18.3 percent of the users use the technology for mobile charging and making petty trades respectively. The major constraints of SPV utilization were awareness gap, price increment and SPV providers shortage comprising of 70, 26.7 and 3.3 percent respectively. Moreover, the result of the binary logit model showed that age and income affected utilization of solar photovoltaic technology significantly with $(\mathrm{P}<0.01$ and $\mathrm{P}<0.1)$ respectively. Similarly, wealth status, awareness creations made, providers of the technology, house quality and price of the technology also affected utilization significantly ( $\mathrm{P}<0.05)$. Conversely, family size, agricultural land size, education level, market access, human capital and quality of technology explanatory variables were assumed to affect utilization, but they do not affected utilization of the technology. Suggesting distribution, financial and government institutions to make awareness, encourage more individuals to be provider of SPV technologies and avail long term credit access in order for the technologies to be bought.
\end{abstract}

Keywords: Adoption, Ethiopia, Gozamin, Solar Photovoltaics, Utilization

\section{Introduction}

Energy is arguably vital component in the development agenda. Access to affordable, reliable and sustainable energy is crucial to achieving many of the Sustainable Development Goals ranging from poverty eradication through advancements in health, education, water supply and industrialization to mitigating climate change [1].

Renewable energy totally contributed $19.3 \%$ of the total energy consumption in 2015. In addition, it has created 9.8 million jobs showing an increment of $1.1 \%$ compared to 2015 [2]. Ethiopia is endowed with renewable energy resources such as hydropower of $45000 \mathrm{MW}$, solar $4-6 \mathrm{Kwh} / \mathrm{m}^{2}$, wind $1350 \mathrm{GW}$, geothermal $7000 \mathrm{MW}$, wood 1120 million tons and others located in different regions of the country [3].

Solar energy is one of the renewable resources that can easily be brought to the rural community through Solar Photovoltaics (SPV). SPV is decentralized, clean and free 
from greenhouse gas (GHG) emissions, reliable and affordable. SPV module prices have fallen rapidly since the end of 2009, to between USD 0.52 and USD $0.72 / \mathrm{W}$ in 2015 [4-6]. At the end of 2016 the total global SPV installation has increased to $303 \mathrm{GW}$ [2]. Of this, Africa is home to $2.1 \mathrm{GW}$ of the world's total and utilization of SPV in Ethiopia (6.5MW) is low mainly used by ethiotelecom to run its landline mobile stations [6-8]. Hence, investment in SPV can bring social, economic and environmental benefits at local, national and global level.

According to the annual report of Gozamin Woreda Water, Irrigation and Energy Office, it had installed a total of 5768 SPV. Of these, 3864 are solar lantern and 1904 are SHS. Lighting, mobile charging, running electrical appliances like Television, Refrigerators, Barbering, Cooking and Pumping water are the area of application. A total of 162 persons have got job opportunity in installation and maintenance, mobile charging, opening cafeterias and restaurants. During the utilization of these technologies' failures happen in undercharging the battery, improper cables connection, presence of shade and dust on modules [9]. Generally, the trend of SPV utilization is increasing from year to year but not at an alarming rate.

Though some increments have been registered, still many rural people in the study area is in deficit of modern electricity. Because out of the 25 kebeles only 5 kebeles are connected to grid according to the report of Gozamin Woreda Water, Irrigation and Energy Office [9]. Grid connection is infeasible as the people are sparsely populated, less energy demand during peak times [10]. Off grid SPV technologies could be best alternative for such kinds of places to deliver modern energy source for lighting [11].

Limited or no adequate studies have been conducted concerning socioeconomic aspects of SPV in the country although Mekuria, Admasu and Mazengia can be mentioned as a few [8, 12-13]. Accordingly, no study has been done regarding the status and determinants of SPV technology utilization by rural households in the specified study area as well as the country. Particularly, there is a knowledge gap in the study area related to issues of SPV awareness, price, availability, suppliers, etc. There is also scarcity of studies on the topic and studies need to be done to solve the energy poverty of the study area in particular. So, this study can contribute in exploring the status and determinants of SPV technology utilization by rural households in Gozamin woreda of Amhara National Regional State, Ethiopia with specific objectives:

a) To assess the status of functionality and pattern of installed SPV technologies among rural households.

b) To analyze determinants of SPV technology utilization in the study area.

c) To determine constraints and opportunities for sustainable utilization of SPV technologies.

\section{Materials and Methods}

\subsection{Description of the Study Area}

Due to high SPV adoption rate, more access to get enumerators and proximity to the town Debre Markos, this study was conducted in Gozamin Woreda, Amhara National Regional State, Ethiopia. According to Gozamin Woreda Water, Irrigation and Energy Office, Gozamin is located at a geographical location of $10^{\circ} 1^{\prime} 46^{\prime \prime}$ 'and $10^{\circ} 35^{\prime} 12^{\prime \prime} \mathrm{N}$ latitudes and $37^{\circ} 23^{\prime} 45^{\prime \prime}$ and $37^{\circ} 55^{\prime} 52^{\prime \prime}$ E longitudes and 300 kilometers far from the capital Addis Ababa [9]. According to Amhara National Regional State Bureau of Finance and Economic Development, the total population of Gozamin Woreda is 145,023 . Of these, males comprise 71,339 while the rest 73,685 are females [14]. According to RETScreen software climate database of National Aeronautics and Space Administration, the woreda has an average daily solar radiation of $5.99 \mathrm{kwh} / \mathrm{m}^{2}$. This is of great potential to adopt SPV in the rural parts of the woreda.

\section{Map of the Study Area}

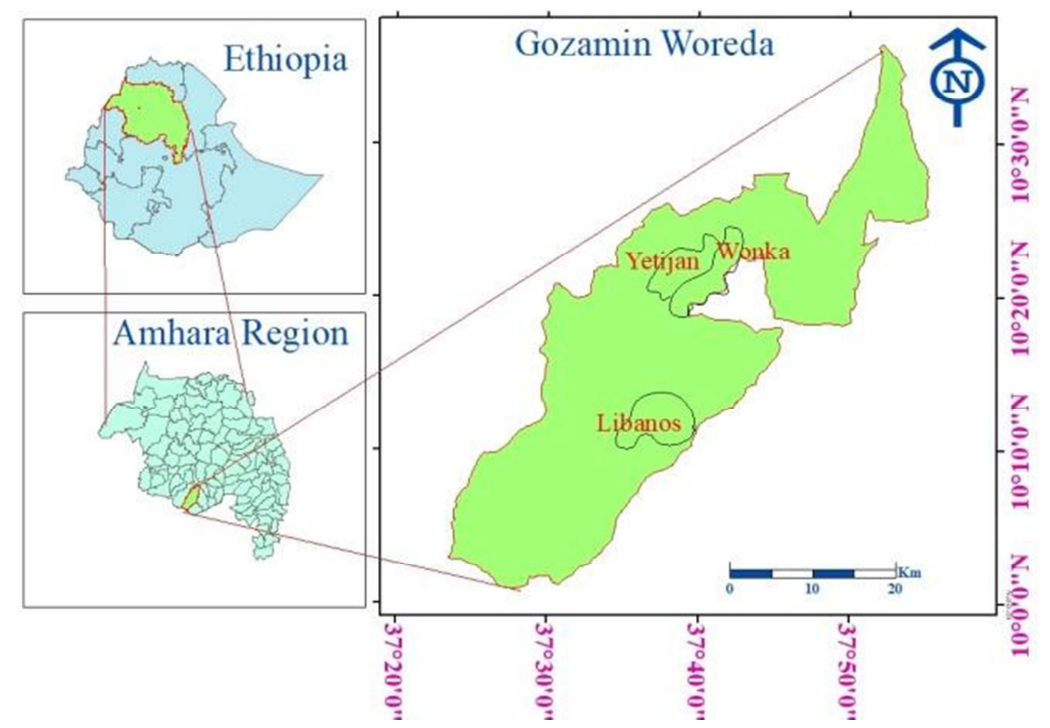

Figure 1. Map of the Study Area. 


\subsection{Methodology}

\subsubsection{Sampling Design}

Probability and non-probability sampling designs were employed in this study. Of the probability sampling designs, simple random and stratified sampling techniques were used. The population of this study, that is, the households of the three rural kebeles (Wonka, Libanos and Yetijan) were selected purposively from the 20 rural kebeles based on higher number of SPV user households, cooperativeness of the study population and proximity to the town Debre Markos.

Table 1. Household Size of Sample Kebeles.

\begin{tabular}{llll}
\hline Kebele & Male & Female & Total \\
\hline Wonka & 505 & 114 & 619 \\
Libanos & 1175 & 197 & 1372 \\
Yetijan & 891 & 81 & 972 \\
Total & 2571 & 392 & 2963 \\
\hline
\end{tabular}

Source: Kebeles' administration offices, 2016 annual report

Next, sample size was determined using Yamane's formula:

$$
n=\frac{N}{1+N(e)}
$$

because the population is definite, where: $\mathrm{n}=$ sample size, $\mathrm{N}=$ the population and $\mathrm{e}=$ the level of precision as cited in Wilson [15]. Based on this formula having a precision level of 7 percent, when computed the result is 190 . The following step was to make stratification of users and non-users of SPV technology based on their utilization or otherwise through proportional allocation method. Hence, 60 and 130 were users and non- users respectively.

\subsubsection{Data Collection Methods}

Both quantitative and qualitative approaches were used to collect data from the sample households. Primary data from household survey, field observation, key informant interview and focus group discussion were collected to achieve the desired goals of the study.

Secondary information from published and unpublished journals, books, conference proceedings, reports, etc. were also collected after they screened for their reliability and suitability on top of primary data to strengthen the overall data and achieve the targets of the study.

\subsubsection{Data Analysis}

For the first and third objective of this study descriptive analysis such as frequencies, percentages, crosstabs were used to analyze the different demographic and socioeconomic characteristics of households such as age, education level, income level, etc.

For objective number two binary logistic regression was employed as the study has binary dependent variable, that is, utilization of SPV (0/1, user/non-user) if the respondent uses SPV technology it is 1 and 0 otherwise. The dependent variable was presumed to be a function of 13 predictor variables.

There are several methods to analyze data involving binary outcomes. However, logit and probit models are popular statistical techniques in relation to explanatory variables that are expected to influence the outcome. Hosmer and Lemeshow pointed out that the logit model has advantages over the other model to analyze dichotomous dependent variable [16]. Because it is an extremely flexible and easily used function and it lends itself to a meaningful interpretation. Hence, according to Hosmer and Lemeshow, the logistic distribution function is econometrically specified as:

$$
P i=\left[\frac{1}{1+e^{-z(i)}}\right]
$$

Where $\mathrm{Pi}$ is the probability of deciding to use SPV technologies for the $i^{\text {th }}$ household and $Z_{(i)}$ is a function of $m$ explanatory variables $\mathrm{X}_{(\mathrm{i})}$ and is expressed as:

$$
Z i=\beta 0+\beta 1+X 1+\beta 2 X 2+\ldots \ldots \ldots \ldots \ldots \ldots \beta m m
$$

Where, $\beta_{0}$ is the intercept and $\beta_{\mathrm{i}}$ are the slope parameter in the model. The slopes tell how the log odds favor of deciding to use SPV technologies changes by unit. The stimulus index, $\mathrm{Z}_{(\mathrm{i})}$, refers to as the log of the odds ratio in favor of deciding the use of SPV. The odds are defined as, the ratio of probability that a household uses SPV Pi to the probability that he will not (1- Pi).

$$
\begin{gathered}
(1-P i)=\left[\frac{1}{1+e^{-z(i)}}\right] \\
\frac{P i}{1-P i}=\left[\frac{1+e^{z(i)}}{1+e^{-Z(i)}}\right]=e^{Z(i)} \\
\frac{P i}{1-P i}=\left[\frac{1+e^{Z(i)}}{1+e^{-Z(i)}}\right]=e^{\beta o}+\sum_{i=1}^{M} \quad \beta i Y i
\end{gathered}
$$

Taking the natural logarithm of the odds ratio of equation (5) will result in what is called the logit model as indicated below:

$$
\ln \frac{P i}{1-P i}=\ln \left[e^{\beta o}+\sum_{i=1}^{M} \quad \beta i Y i\right]+Z i
$$

If the disturbance term $\mathrm{U}_{\mathrm{i}}$ is taken in to account, the logit model is specified as:

$$
Z i=\beta 0+\Sigma \beta i X i+U i
$$

Where $Z_{i}=$ the $\log$ odds ratio in favor of use of SPV, $\beta_{0}=$ intercept term, $\beta i=$ parameters to be estimated, $X i=$ hypothesized determinants, $U i=$ disturbance term

Results about the effect of these factors on household's SPV utilization status was analyzed using Statistical Packages for Social Science, SPSS 16.0.

\section{Results and Discussion}

\subsection{Frequency of Users and Functionality of Technologies}

Of the total respondents 31.5 and 68.5 percent were users and non-users of SPV technologies respectively. This outcome showed the frequency of users and discussed by a study of Keriri that out of the total respondents' 33 percent of them were installing and using the SPV technologies [17]. 
This implies that most of the respondents were not users. Presence of awareness problem, low income level and having no belief in the technology are some of the reasons that justify this finding.

The technologies used by users at the time of interview were all functional. Rooftop proper handling is assumed to be the main reason for functionality of the technology. But some interruptions happened due to technical, weather condition and other reasons. This was elucidated by 21.7 and 1.7 percent of the users that their SPV technologies fail to function once and twice per month respectively. A study by Murali et al. showed that due to monsoon seasons, SPV fail to function up to three times per month because the sun cannot shine as there is heavy cloud and rain may be for prolonged time in a day or weeks [18]. Hence, in the study area the case is strongly similar especially during the rainy season.

Table 2. Monthly Failure of SPV Technologies.

\begin{tabular}{lll}
\hline Frequency of Failure Per Month & Number & Percent \\
\hline None & 46 & 76.7 \\
Once & 13 & 21.7 \\
Twice & 1 & 1.7 \\
\hline
\end{tabular}

Source: Own survey, 2018

\subsection{Patterns of SPV Technology Use}

All the users (60) used SPV technologies mainly for lighting purpose. In addition to lighting, 81.6 percent users used for mobile charging and 18.4 percent for making petty trades like opening small cafeterias and restaurants.

Table 3. Patterns of SPV Use.

\begin{tabular}{lll}
\hline Patterns of SPV Use & Number & Percent \\
\hline Lighting and Mobile charging & 49 & 81.6 \\
Lighting and Petty Trade & 11 & 18.4 \\
\hline
\end{tabular}

Source: Own survey, 2018

As indicated in table (3), the major pattern of SPV use is lighting responded by all (60) respondents. This result agreed with Hannah et al. in that 89 percent of the respondents were taking advantage to undertake education for their children; furthermore, health and hygiene improvements were gained by 89 percent of respondents because of the presence of light from SPV [19]. Lighting as a major pattern could be explained by the fact that women use light in the night for cooking dinner, for strengthening social interactions with neighbors at the sunset using coffee ceremony, reducing or lessening the risk of fatal kerosene lamp accidents and to be secured from robbers in the nightfall.

Table 4. The Maximum Likelihood Estimates of Binary Logit Model.

\begin{tabular}{|c|c|c|c|c|c|}
\hline Variables & Estimated Coefficient (B) & Standard Error (S.E). & Wald Statistics & Significance Level (Sig.) & Odds Ratio $\operatorname{Exp}(B)$ \\
\hline Price & -1.058 & .510 & 4.306 & $.038 * *$ & .347 \\
\hline Market & .073 & .337 & .046 & .829 & 1.075 \\
\hline Quality & .607 & .447 & 1.845 & .174 & 1.835 \\
\hline Education & .316 & .401 & .623 & .430 & 1.372 \\
\hline Income & .001 & .001 & 3.828 & $.050 *$ & 1.001 \\
\hline Age & -.414 & .072 & 32.759 & $.000 * * *$ & .661 \\
\hline Family & .220 & .274 & .644 & .422 & 1.246 \\
\hline Land & -.521 & .481 & 1.172 & .279 & .594 \\
\hline Awareness & 1.199 & .476 & 6.352 & $.012 * *$ & 3.318 \\
\hline Providers & 1.044 & .397 & 6.915 & $.009 * * *$ & 2.841 \\
\hline House & 1.297 & .569 & 5.191 & $.023 * *$ & 3.657 \\
\hline Human & .034 & .415 & .007 & .934 & 1.035 \\
\hline Wealth & 1.151 & .571 & 4.071 & $.044 * *$ & 3.163 \\
\hline Constant & 16.261 & 3.310 & 24.141 & .000 & $1.154 \mathrm{E} 7$ \\
\hline
\end{tabular}

Source: Own survey, 2018

Exp (B) shows the predicted changes in the odds for a unit increase in the predictor.

Omnibus Tests of model coefficients: chi-square 167.865 sig. 0.000

Percentage of correct prediction $92.1 \% ; \mathrm{N}=190$

$*, * *$, and $* * *$ significant at $0.1,0.05$, and 0.01 level respectively

\subsection{Determinant Factors Affecting Utilization of SPV Technologies}

The binary logit model revealed that seven variables only were found to be significant to utilization of SPV technologies (Table 4). These were age and income level of respondents with significance level of $(p<0.01)$ and $(p<0.1)$ respectively. Outlook of price of SPV technologies by respondents, wealth status of respondents, awareness creations made to respondents, sufficiency of SPV providers locally, and house type of respondents were also significant at $(\mathrm{p}<0.05)$ level. Only significant variables are discussed hereunder.

\subsubsection{Wealth Status of Respondents}

Wealth status is found to be positive and significant at $(\mathrm{P}<0.01)$. Households with better-off wealth are 3.163 more likely to adopt and utilize SPV technologies. This result was consistent with the findings of Khandker et al. as wealthier households' do not hesitate to utilize the technology in frustrating the high upfront cost [20]. This could be due to the fact that households' having higher overall assets, this in turn, may help them to pass a decision on utilization of SPV. 


\subsubsection{Outlook of SPV Price by Respondents}

As expected, a significant negative relationship between price and utilization of SPV technologies at $(\mathrm{P}<0.05)$ was found. Price was found to decrease the probability of households' decision by a factor of 0.347 . The study of Khandker et al. discussed that for every 100 Taka increase in price, there was a decrease in the probability of utilization by 2 percent [20]. The result was also highlighted by Qureshi et al. that high initial cost and inability to finance SPV systems prevented all the respondents from using these technologies [21]. This could be explained by the fact that as the price of SPV technology increases by a unit price, probability of decision on utilization of SPV technology decreases by respondents.

\subsubsection{Awareness Creations Made to Respondents}

Awareness in this study may refer to the provision of relevant information in person to the households about SPV where they can be purchased, the prices, the benefits, the drawbacks, etc. As the analytical result of binary model indicated, households who obtained awareness about SPV technologies were found to be positively related with utilization of SPV at $(\mathrm{P}<0.05)$. The odds ratio also in favor of decision on SPV utilization by a factor of 3.318 for a unit increase in households awareness. This finding is similarly indicated by Keriri and $\mathrm{Ng}$ 'eno in that there is a positive correlation between awareness and SPV utilization [17, 22]. This could be explained by the fact that awareness that households gain from government or other bodies help them to get the knowledge and take initiation for passing rational decision on utilization of SPV technologies.

\subsubsection{Age of Respondents}

The binary model shows that age was negatively and significantly related to utilization of SPV at $(\mathrm{P}<0.01)$. For one-year increment in age, utilization of SPV technologies decrease by a factor of 0.661 . This result complied with the study of Vasseur and Kemp in that users were younger than non-users [23]. This can be due to eagerness to accept, test and get functions of the technologies is higher by younger than older.

\subsubsection{Income Level of Respondents}

The binary logit model result showed that income level of respondents is positively related to the utilization of SPV technologies with $(\mathrm{P}<0.1)$. Hence, the result indicated that utilization of SPV technologies is higher by a factor of 1.001 for those who have one-unit income increment than their counterparts. This result agreed with the study of Khandker et al. [20]. On the other hand, low income level of households prevents them from buying these technologies as stated by Feron [24]. This can be explained by the fact that as the income level is high, the probability of utilization rate also increases.

\subsubsection{House Type of Respondents}

Based on the result of binary logit model, the relationship was significant $(\mathrm{P}<0.05)$ with utilization of SPV technologies.
Hence, households living in quality house were able to pass decision to use SPV technologies by a factor of 3.657 higher than their counterparts, those who live in poor house. This result corresponds with study of Khandker et al. in that housing structure (built in bricks) is one of the influencing factors for use of SPV [20]. This may be explained by the fact that as the household gets wealthier and earn more income, the household keeps quality house by building from quality raw materials. Thus, household affords to buy SPV since the price of SPV may be very much smaller as compared to cost to keep quality house.

\subsubsection{Sufficiency of Providers of SPV Technology}

The result of the model showed that households that said there were sufficient number of providers of SPV significantly related with the use of SPV at $(\mathrm{P}<0.05)$. A factor of 2.841 odds ratio in favor of the decision to use SPV for those that said there were sufficient number of providers of SPV higher than their counterparts.

While other remaining factors such as educational level of respondents, perception of households on quality of SPV, local market access of SPV, family size of respondents, agricultural land size and human capital of respondents were not affecting the use of SPV technologies significantly.

\subsection{Constraints and Opportunities of SPV Technologies for Sustainable Use}

\subsubsection{Constraints of SPV Technologies}

The basic constraints identified by the users were awareness gap, price increment and provider shortage comprising of 70, 26.7 and 3.3 percent respectively (figure 2). Here, one can notice that awareness gap was a major challenge hindering rural communities from using SPV technology. As households were with no information on the price, where the technologies are found, the way to manipulate for daily use, how to maintain when defects happen, etc., households' decision to use these technologies decreased. This result agreed with Chaurey and Kandpal that when there is no or low awareness, decision to use SPV dwindles and as a result dissemination of SPV remains low [25]. The possible reason behind this finding is assumed to be little or no awareness creations made about SPV by extension agents.

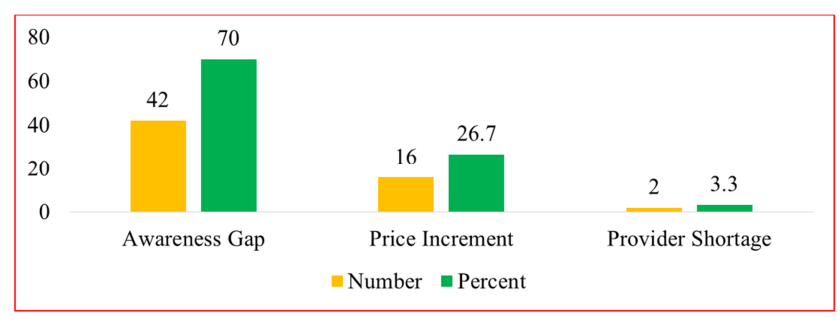

Source: Own survey, 2018

Figure 2. Constraints of Utilization of SPV Technologies.

About 58.3, 33.3, 6.7, 1.7 percent of users were giving a response that a SPV technology was very expensive, expensive, cheap and very cheap respectively. This agrees 
with price increment raised by 26.7 percent of the user respondents (figure 2) making not to be affordable so that the use of SPV technologies becomes difficult in rural communities.

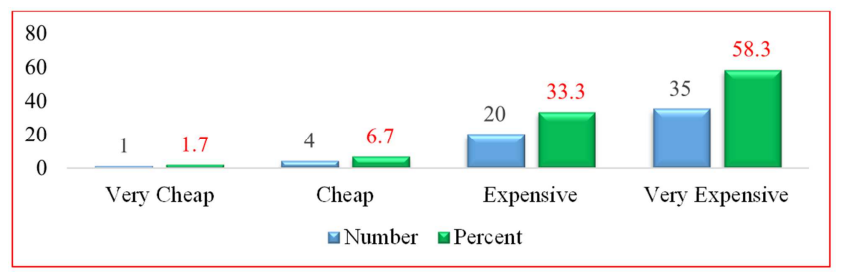

Source: Own survey, 2018

Figure 3. Affordability Challenge of SPV Technologies.

Affordability of SPV as indicated in figure (3), is very expensive by most ( 58.3 percent) of the respondents. This result complied with Feron in which high initial investment costs made SPV unattainable by the rural communities [24]. This finding could be explained by the fact that when households are economically deprived and not in a strong bargaining position to negotiate, the acquisition of SPV decreases, except for the rural elite.

Users of solar lantern were asked to evaluate the durability of the technology and most of the respondents about 55.3 percent responded that the SPV durability is very good followed by 21.4 percent respondents who said excellent. Contrary to this, few about 16 percent and 7.1 percent responded that SPV durability is good and bad respectively.

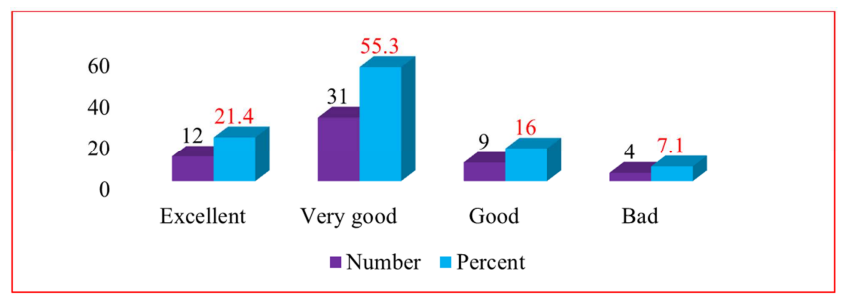

Source: Own survey, 2018

Figure 4. Durability of SPV Technologies.

This result agreed with Hemmen in that SPV can be used for up to a period of 40 years [26]. Moreover, similar results from Nigeria by Ugulu showed that 72 percent of the respondents were using up to 4 years without any problem [27]. The possible reason for this finding could be proper roof top installation and handling of SPV. Consequently, SPV could not be easily destroyed and damaged with animals or human beings in the ground. Eventually, durability implies the opportunity of SPV the technologies.

\subsubsection{Opportunities of SPV Technologies}

Though all those constraints to use SPV technologies, they have some opportunities as distinguished by focus group discussants in saving time, money and effort to have light; and keeping the health of especially women and children by avoiding the black soot of kerosene wick lamps during the night time.

\section{Conclusion and Recommendation}

\subsection{Conclusion}

In order to assess the current status of installed SPV technologies among rural households in terms of frequency of users, functionality and pattern of use as household energy source, a total of 190 sample households taken and 31.5 percent of them were users of SPV technologies.

Regarding functionality of the technologies, the descriptive results indicated that all (60) of the installed SPV were operational during the survey time. Installing the SPV at the rooftop by most households kept the technologies from damage by animals as well as human beings. This contributed to be functional up to a period of 5 years. There were intermittencies of SPV to supply the required power due to weather conditions and technical skill incapability. So, proper installment and management enhances functionality of SPV technologies.

Lighting from SPV is the major pattern of use. It was evident from the group discussion time, it keeps the health of especially women and children by replacing kerosene wick lamps, reducing fatal kerosene lamp accidents and a means to secure the house from robbers at nightfall. Therefore, utilization of SPV brought significant reduction (almost by half) fossil fuel energy sources for light.

In order to identify determinant factors affecting utilization of SPV technologies in the study area, a total of 13 explanatory variables were included for the analysis in the binary logistic regression model. The result showed that among the hypothesized variables seven variables were found to be significantly related to the utilization of SPV technologies. The likelihood of utilization is higher with lower age of the household head (household characteristics), an increase in awareness creations made, sufficiency of providers of SPV (institutional factors) and an increase in wealth status, house quality and income level (socioeconomic factors). However, it is likely to be lower with increase in price. Hence, the findings of this study highlight the above likelihood for sustainable utilization of SPV technologies.

Awareness gap, high upfront cost or initial investment cost, unavailability of long-term credit access and inaccessibility of spare parts (PV system components) were the reasons distinguished as a constraint for sustainable use of SPV. Therefore, due to these limitations large portion (68.5 percent) of households in the study area were found to be discouraged from using SPV technologies.

Durability, reduction of time, effort and money, keeping the health of women and children and environmental protection were some of the opportunities of SPV technologies.

\subsection{Recommendations}

Based on the findings of the study, the following recommendations can be suggested:

Every supportive effort for SPV utilization will be ineffective until the households are not fully aware of SPV technology benefits and drawbacks. The government agencies 
and providers along with other concerned organizations should strengthen and continue to aware the rural people and nominate the authentic shops from where people can buy quality SPV.

Shortage of SPV providers was also found statistically significant in relation to the use of SPV technologies; hence, the woreda trade office should encourage more individuals to participate in the provision and delivery of the technologies.

No access to long term credit schemes and less availability of spare parts of technologies were some of the constraints for fast utilization of SPV technologies. So, financial and distribution institutions should give due attention to resolve such kinds of problems.

Most households in the study area manage their SPV by installing at the rooftop to get power but subjected to shade and dust. Thus, reducing power output. So, attention and technical support should be given to reverse the problem.

The extent of utilization of SPV at zone, region and country level were not addressed with many more explanatory variables and larger sample size. Hence, further and detail study about the extent of SPV utilization in both urban and rural areas at the stated different levels is essential.

\section{Acknowledgements}

First and foremost, I express my sincere gratitude to my advisor, Dr. Yemiru Tesfaye, for his constructive comments, suggestions and supports for victorious completion of this paper. Next, I need to extend my earnest appreciation to MRV project for offering financial support to this study. I am also thankful for all the respondents and enumerators who gave me reliable and concrete information during the survey time. Finally, I would like to acknowledge my beloved wife Wubsira Bitew and my cute son Kidus Yared for their continued encouragement to carry out this study successfully.

\section{References}

[1] UN, 2016. The Sustainable Development Goals Report, New York.

[2] REN21, 2017. Renewables 2017 Global Status Report, Paris.

[3] Derbew, D., 2013. Ethiopia's Renewable Energy Power Potential and Development Opportunities. Ministry of Water and Energy: Abu Dhabi, UAE.

[4] Schützeichel, H., 2012. Ethiopia solar.

[5] Solanki, C. S., 2015. Solar photovoltaics: fundamentals, technologies and applications. PHI Learning Pvt. Ltd.

[6] IRENA, 2016. Solar PV in Africa: Costs and Markets.

[7] MoWIE, 2013. Updated Rapid Assessment and Gap Analysis on Sustaiable Energy for All, Addis Ababa.

[8] Mekuria E., 2016. Challenges and Prospects of Solar Home System Dessimination in Rural Prats of Ethiopia, The case of Solar Energy Foundation, MSc Thesis. Addis Ababa University, Addis Ababa.
[9] Gozamin Woreda Water, Irrigation and Energy Office Annual Report, 2016. Debre Markos.

[10] Tania Urmee, D. H.-G. H., 2016. Photovoltaics for Rural Electrification in Developing Countries. Switzerland: Springer.

[11] Mohanty, P., Sharma, K. R., Gujar, M., Kolhe, M. and Azmi, A. N., 2016. PV System Design for Off-Grid Applications. In Solar Photovoltaic System Applications (pp. 49-83). Springer, Cham.

[12] Admasu, A. A., 2011. Solar PV based rural electrification in Rema rural village.

[13] Mazengia, D. H., 2010. Ethiopian Energy Systems: Potentials, Opportunities and Sustainable Utilization.

[14] Amhara National Regional State Bureau of Finance and Economic Development, BoFED 2013 Bahir Dar.

[15] Wilson, J., 2014. Essentials of business research: A guide to doing your research project. Sage.

[16] Hosmer, D. W. and Lemeshow, S., 2000. Applied Logistic Regression 2nd edn Wiley-Interscience Publication.

[17] Keriri, I. K., 2013. Factors Influencing Adoption of Solar Technology in Lakipia, North Constituency, Kenya, Nairobi, Kenya.

[18] Murali, R., Malhotra, S., Palit, D. and Sasmal, K., 2015. Socio-technical assessment of solar photovoltaic systems implemented for rural electrification in selected villages of Sundarbans region of India (Doctoral dissertation, TERI University).

[19] Hannah Müggenburg, Annika Tillmans, Petra Schweizer-Ries, Tim Raabe, Peter Adelmann, 2011. Social acceptance of PicoPV systems as a means of rural electrification - A socio-technical case study in Ethiopia.

[20] Khandker, S. R., Samad, H. A., Sadeque, Z. K., Asaduzzaman, M., Yunus, M. and Haque, A. E., 2014. Surge in solar-powered homes: Experience in off-grid rural Bangladesh. World Bank Publications.

[21] Qureshi, T. M., Ullah, K. and Arentsen, M. J., 2017. Factors responsible for solar PV adoption at household level: A case of Lahore, Pakistan. Renewable and Sustainable Energy Reviews, 78, pp. 754-763.

[22] NG'ENO, N. C., FACTORS AFFECTING THE ADOPTION OF SOLAR POWER FOR DOMESTIC USAGE IN KAJIADO COUNTY, KENYA.

[23] Vasseur, V. and Kemp, R., 2015. The adoption of PV in the Netherlands: A statistical analysis of adoption factors. Renewable and Sustainable Energy Reviews, 41, pp. 483-494.

[24] Feron, S., 2016. Sustainability of off-grid photovoltaic systems for rural electrification in developing countries: a review. Sustainability, 8 (12), p. 1326.

[25] Chaurey, A. and Kandpal, T. C., 2010. Assessment and evaluation of PV based decentralized rural electrification: An overview. Renewable and Sustainable Energy Reviews, 14 (8), pp. 2266-2278.

[26] VAN HEMMEN, H. A. N. N. A. H., 2011. DETERMINANTS OF INTERNATIONAL SOLAR PANEL ADOPTION. ENVIRONMENTAL SCIENCE. 
[27] Ugulu, A. I., 2016. The determinants of decentralised photovoltaic $(P V)$ adoption in urban Nigeria and a verified model for rapid diffusion (Doctoral dissertation, Heriot-Watt University). 